\title{
ILMU DAN HIKMAH \\ DALAM PERSPEKTIF DAKWAH NABI
}

\author{
Abdul Kadir \\ kadir@stidnatsir.ac.id \\ Program Studi Komunikasi Penyiaran Islam \\ Sekolah Tinggi Ilmu Da'wah Mohammad Natsir, Indonesia
}

\begin{abstract}
ABSTRAK
Tujuan Penelitian: Untuk mengetahui ilmu dan hikmah dalam perspektif da'wah Nabi. Metode Penelitian: Kualitatif. Hasil Penelitian: Seorang da'i harus memiliki ilmu tentang cara-cara berdakwah dan materi yang akan didakwahkannya, seorang da'i juga harus menyampaikan dakwahnya dengan hikmah atau penuh kebijaksanaan dan kelemahlembutan. Jika dua prinsip ini tidak dimiliki seorang da'i, maka bisa jadi dakwahnya malah akan menimbulkan kerusakan dan menyebabkan orang lain memandang negatif terhadap dakwah.
\end{abstract}

Kata Kunci: Dakwah, ilmu, hikmah.

\section{PENDAHULUAN}

Sampai hari ini bahasan tentang dakwah Nabi Muhammad SAW. Masih terasa relevan untuk dibahas, dikupas dan dibicarakan. Baik mengenai cara, metode atau prinsif-prinsif dakwah Islam. Dan ini terus menjadi bahasan yang dikaji dan dibahas para ulama. Tidak sedikit para ulama terdahulu atau juga kontempoter hingga saat ini masih terus membahas dan mengkajinya. Seolah bahasan yang tak kunjung usai untuk dikaji dan dibicarakan. Para ulama berusaha tak henti-hentinya menjelaskan dan menerangkannya kepada ummat agar mereka berdakwah sebagaimana Rasulallah saw berdakwah.

Kenapa dakwah ini terus dikaji dan dibahas para ulama, karena ini akan terus berlangsung sampai kapan pun dan dibelahan dunia mana pun. Dan akan terus berlangsung selama roda kehidupan manusia muslim masih eksis. Dan kebutuhan manusia akan dakwah Islam ini adalah sesuatu yang maklum dan 
sebuah keniscayaan. Manusia sangat membutuhkan orang yang menerangi dan membawa mereka ke jalan yang lurus. ${ }^{1}$

Selain metode, prinsip-prinsip dan cara berdakwah yang dikaji para ulama ini dan terkadang masing-masing kalangan belum sepakat dalam memahami dan mengimplementasikan kata dakwah ini. Selain, tidak sedikit dari para da'i yang berdakwah tanpa dibarengi ilmu dan hikmah. Bahkan, ada pula yang justru memanipulasi dakwah untuk sebuah kepentingan. ${ }^{2}$ Allah musta'an.

Untuk itu, dakwah dengan ilmu dan hikmah dalam perspektif dakwah Nabi saw amat menarik untuk dikaji dan dibahas. Inilah dakwah yang dilakukan Nabi saw dan para sahabatnya. Memang, dakwah dengan ilmu dan hikmah ini tidaklah mudah kalau kita lihat kondisi sekarang ini yang penuh dengan tantangan dan terkadang juga kesalahpahaman orang melihat jalan dakwah Islam. Namun, bukankah jalan dakwah dengan ilmu dan hikmah ini juga tetap butuh kesabaran tinggi, ketulusan dan optimisme yang tinggi. Karena dengan inilah dakwah dapat berlangsung terus dan akan menuai keberhasilan serta tersebarnya pemahaman Islam yang benar di masyarakat. Sekali lagi, memang tidaklah mudah menerapkan ilmu dan hikmah dalam konsep dakwah Islam, atau dengan istilah lain dengan sebutan 'lurus lembut' jelas amat memerlukan ketawadhuan, ketegaran, keikhlasan, ketulusan dan optimisme yang tinggi dan yang lebih penting dibarengi dengan pemahaman yang benar dan komprehensif. Walau demikian, dakwah dengan ilmu dan hikmah 'dakwah lurus lembut' inilah yang mendatangkan kemaslahatan dan kebaikan untuk umat, serta dapat menghilangkan kesalahpahan yang selama ini muncul.

Sebagai contohnya adalah menerapkan sikap tegas dalam dakwah Islam, karena sikap tegas merupakan bagian dari ilmu dan hikmah dalam dakwah. Maka sikap tegas ini tidak berarti harus kasar apalagi bengis. Tidak, tentu tidak. Tetapi ketegasan dalam koridor kelembutan. Bukankah nasehat yang lembut dapat meluluhkan hati yang keras. Dan bukankah pula, nasehat dari hati yang dalam dapat menuntun hidayah Allah ta'ala. ${ }^{3}$ Dan sikap itulah yang terus dinasehatkan para ulama ablussunnab dari dahulu hingga sekarang.

Karena itulah tidak sedikit para ulama menulis, mengkaji dan membahasnya. Banyak hasil karya dan tulisan para ulama tentang masalah ini, juga mereka menjelaskan metode dan cara, serta problem dakwah Islam yang melingkupinya. Agar du'at dan umumnya masyarakat muslim bisa memahami dan

${ }^{1}$ Fawwaz bin Hulayyil as-Suhaimi, Begini Seharusnya Berdakwah, Jakarta: Darul Haq, 2011, hal 20.

${ }^{2}$ Prof. Rabi bin Hadi al-Madhali, Fiqih Dakwah Para Nabi, Bogor: Media Tarbiyah, 2006, lihat pengantar.

${ }^{3}$ Sebagai sebuah bahan kajian lihat Fiqh Nasehat, dalam edisi terbaru Tepat Memberi Nasehat Adab dan Tata Cara Memberi Nasehat, Fariq Gasim Anuz, Jakarta: Daun, 2013. 
melakukan cara ini di tengah-tengah umat dan bangsa ini dengan pemahaman dakwah Islam yang benar, dakwah Islam yang Rahmatan lil a'lamin, sesuai dengan tuntunan Allah dan Rasul-Nya.

Sebagai contoh yang dapat disebutkan, salah satunya adalah buku yang berjudul Usus Manbaj as-Salaf Fi ad-Da'wah ilallah yang ditulis oleh Fawwaj bin Hulayyil bin Rabah as-Suhaimi. Atau juga buku lain yaitu, Manhajul Ambiya' Fid Da'wah ilallah fibl Hikmah Wal 'Aql karya Syaikh Prof. Rabi' bin Hadi al-Madhali, Guru Besar Universitas Madinah, Saudi Arabia. Atau juga buku yang ditulis oleh Dr. Abdul Karim Zaidan, Ushûl al-Da'wah, dasar-dasar Ilmu Da'wah. Yang terakhir ini merupakan buku lama yang menjadi bacaan dan kajian para da'i. Dan buku-buku atau karya-karya ulama lainnya.

Suatu hal yang tidak dapat dipungkiri bahwa dakwah merupakan jalan mulia para Nabi dan Rasul ${ }^{4}$, jalan yang penuh dengan rintangan, tantangan, onak dan duri. Namun, Allah ta'ala yang Maha Pengasih dan Penyayang menjanjikan ganjaran yang besar untuk para penempuhnya. Nabi saw bersabda: "Barangsiapa yang menyeru kepada petunjuk, maka ia mendapatkan pahala seperti pahala orang yang mengikutinya, dan bal itu tidak mengurangi dari pahala-pabala mereka sedikitpun. Dan barangsiapa yang menyeru kepada kesesatan, maka ia mendapatkan dosa seperti dosa orang yang mengikutinya, dan hal itu tidak mengurangi dari dosa-dosa mereka sedikit pun. ${ }^{5}$

Menyiarkan dakwah Islam bagi seorang da’i adalah sebuah kewajiban dan juga bagi setiap individu muslim apa pun pekerjaan dan profesinya. Dimana pun ia bekerja manakala ia bersikap dan berlaku sebagaimana tuntunan Allah dan Rasulnya, maka itu menjadi sebuah dakwah bagi orang lain. Baik dengan akhlak yang baik, menunjuki kebaikan, mengajari ilmu yang bermanfaat atau mengajari orang yang belum bisa surat al-Fatihah maka itu menjadi pahala tersendiri untuknya. Dan dengan adanya dakwah ini pula, Islam menjadi kokoh dan tegak.

Dakwah menyeru ke jalan Allah ta'ala merupakan sebesar-besarnya ketaatan kepada Allah, dan sebaik-baiknya perkataan seorang hamba adalah ajakan kepada manusia untuk menuju jalan Allah dan beramal shalih, inilah yang ditegaskan Allah ta'ala dalam kitab-Nya. Allah Ta'ala befirman:

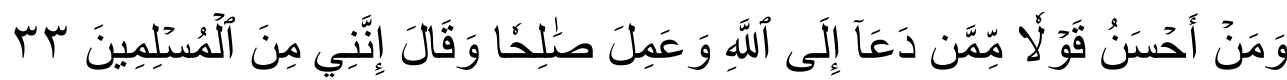

Siapakah yang lebih baik, perkataannya daripada orang yang menyeru kepada Allah, mengerjakan amal yang saleh, dan berkata: "Sesunggubnya aku Termasuk orangorang yang menyerah diri?" (Fushilat: 33).

\footnotetext{
${ }^{4}$ Lihat al-Qur'an surat al-Ambiya: 25, al-An'am: 162-163, Fushilat: 33.

${ }^{5}$ Shahih Muslim, dalam kitab al-'ilmu, dalam bab man sanna Sunnatan Hasanatan... no. 2674.
} 
Namun, tidak sedikit para penyeru dakwah Islam yang tidak berpijak pada tuntunan sunnah, as-sunnah al-ambiya war rasul fid da'wah. Hanya bermodal semangat tanpa dibarengi ilmu atau berdakwah tidak berbekal ilmu, maka hal itu adalah sesuatu yang tercela. Imam Bukhari, dalam kitab shahihnya secara khusus membuat satu bab, 'al-ilmu qobla qaul wal amal', ilmu harus lebib dabulu sebelum perkataan dan perbuatan ${ }^{6}$. Bahkan, yang lebih parah lagi ada yang menafikan keutamaan metode dakwah para Nabi dan Rasul ini. Jika itu terjadi, justru akan terjerumus dalam berbagai kesalahan dan kekeliruan yang tidak disadarinya. Allah musta'aan.

Oleh karenanya, dibutuhkan metode dakwah yang benar, dan metode yang benar itu tidak lain mengacu pada al-Qur'an dan as-Sunnah dengan pemahaman para sahabat. Atau dakwah dalam perspektif sunnah Nabi saw dan para sahabatnya. Inilah yang perlu dikaji dan ditelaah lebih dalam. Karena inilah jalan dakwah yang selamat. Dan jalan inilah yang mendatangkan limpahan berkah, ilmu dan mendatangkan kejernihan akal.

Tulisan ini mencoba mengangkat alur dakwah Islam dari sisi Ilmu, hikmah dalam kewajiban menyiarkan dakwah Islam. Sebagaimana pula Nabi saw dan para sahabatnya melakukannya. Dan penulis berusaha menukil karya-karya ulama ablussunnah dalam masalah ini. Sehingga berharap menjadi bahan kajian, renungan dan penelusuran kita bersama. Amien.

\section{Pengertian dan Definisi}

Ilmu disebut pula dengan bashirah, sebagaimana disebutkan al-Qur'an dalam surat Yusuf ayat 108. Dengan ilmu pula berbagai syubhat dan kebatilan dapat ditundukan dengan kebenaran. ${ }^{7}$

Ada pun hikmah sebagaimana disebutkan Ibnu Manzhur dalam Lisanul Arab, sebagaimana dikutif oleh Dr. Zaid Abdul Kariem dalam al-Hikmah fid Da'wah Ilallah 'Dakwah bil Hikmah', disebutkan bahwa hikmah adalah keadilan, ilmu, kelembutan, nubuwah, al-Qur'an ... ${ }^{8}$ Kata hikmah dalam al-Qur'an dengan berbagai pengertian yang beragam disebutkan lebih dari dua puluh kali.

\footnotetext{
${ }^{6}$ Shahih Bukhari, Juz I dalam kitabul Iman.

${ }^{7}$ Lihat Rabi bin Hadi al-Madhali, Fiqih Dakwah Para Nabi, Bogor: Media Tarbiyah, 2006, lihat kata pengantar hal 2-3.

${ }^{8}$ Dr. Zaid Abdul Kariem az-Zaid, al-Hikmah fid Da'wah Ilallah diterbitkan dengan edisi 'Dakwah bil Hikmah', Jakarta: 1412, alKautsar, 15.
} 
Disebutkan pula kata hikmah merupakan kata ungkapan pengetahuan mengenai sesuatu yang paling baik, dengan landasan ilmu yang terbaik. ${ }^{9}$ Jadi hikmah menurut pokok bahasan adalah mengisyaratkan pencegahan perbuatan zhalim, membimbing pada kebaikan yang didasarkan pada ilmu pengetahuan. Jadi dapat dikatakan, hikmah pada prinsipnya adalah mencari kebenaran yang didasarkan pada ilmu. ${ }^{10}$

Adapun definisi dakwah secara bebas adalah suatu proses penyampaian informasi Ilabiyah kepada para hamba manusia yang merupakan bagian integral dari hidup dan kehidupan setiap individu muslim.

Kata dakwah berasal dari bahasa Arab yang berarti seruan, panggilan atau ajakan. ${ }^{11}$ Arti demikian sering kita jumpai dalam al-Qur'an al-Kariem. Sebagaimana terdapat dalam al-Qur'an diantaranya terdapat dalam surat Yunus: 25, Yusuf: 33 dan surat al-Baqarah: 221.

Menurut Fawwaz bin Hulayyil as-Suhaimi, ${ }^{12}$ Dakwah secara syara' adalah mengajak orang lain agar melakukan segala perintah Allah, baik berupa ucapan maupun amalan, dan meninggalkan segala larangan Allah, baik berupa ucapan atau perbuatan ${ }^{13}$.

Ada pun pengertian dakwah secara syara' sebagaimana disebutkan, $\mathrm{KH}$. A. Syamsuri Siddiq ${ }^{14}$, adalah segala usaha dan kegiatan yang sengaja dan berencana dalam wujud sikap, ucapan dan perbuatan yang mengandung ajakan dan seruan, baik langsung maupun tidak langsung yang ditujukan kepada orang perorangan, masyarakat maupun golongan supaya tergugah jiwanya, terpanggil hatinya kepada ajaran Islam untuk selanjutnya mempelajari dan menghayati serta mengamalkannya dalam kehidupan sehari-hari. ${ }^{15}$

${ }^{9}$ Dr. Zaid Abdul Kariem az-Zaid, al-Hikmah fid Da'wah Ilallah diterbitkan dengan edisi 'Dakwah bil Hikmah', Ibid hal 14.

${ }^{10} \mathrm{Ibid}$, hal 16.

11 Lihat Dr. Abdul Karim Zaidan, Ushûl al-Da'wah, dasar-dasar Ilmu Dakwah (Jakarta:1980,Media Dakwah),hal 373. Lihat juga Prof. Toha Jahja Umar, Ilmu Da'wah, Jakarta: 1971, Widjaya Djakarta, hal 1, lihat pula Munzier Suparta, (editior), Metode Dakwah, Jakarta: Kencana, 2003, hal 62.

${ }^{12}$ Mahasiswa yang pernah menamatkan program S2 di Universitas Madinah, Saudi Arabia, dengan tesis berjudul Usus Manhaj as-Salaf Fi ad-Da'wah ilallah, Begini Seharusnya Berdakwah, yang kemudian dibukukan tahun $1421 \mathrm{H}$.

${ }^{13}$ Fawwaz bin Hulayyil as-Suhaimi, Begini Seharusnya Berdakwah, Jakarta: Darul Haq, 2011, hal 19.

${ }^{14}$ Beliau dahulunya adalah salah seorang dosen fakultas Ushuluddin, Universitas Islam Bandung, UNISBA Bandung, dan bukunya ini mendapat apresiasi dari Rektor UNISBA KH. EZ. Muttaqien tahun 1981.

${ }^{15}$ KH. A. Syamsuri Siddiq, Da'wah \& Teknik Berhutbah, Bandung: PT. Alma'arif, 1981, hal 8. 
Bila disebut kata mendakwahkan, hal itu mempunyai arti menyampaikan sesuatu kenyakinan. ${ }^{16}$ Atau mendakwahkan sesuatu kenyakinan yang ia anggap itu merupakan sesuatu kebenaran. Sedangkan orang yang melakukan seruan adalah da’i (orang yang menyeru).

Menyampaikan risalah dakwah adalah tugas setiap muslim. Karena Islam adalah agama dakwah. Maka setiap muslim mempunyai tugas untuk menyampaikan dakwah Islam ini di tengah-tengah umat. Dan tentunya tugas ini sesuai dengan ilmu dan kemampuannya masing-masing dan dibidang atau diprofesinya masing-masing.

Bahkan, dengan terang dan gamblang al-Qur'an menjelaskan bahwa dakwah adalah suatu kewajiban bagi setiap muslim. Allah Swt memerintahkan umat Islam untuk menjadi umat yang menyeru kepada kebaikan dan mencegah kepada kemungkaran (lihat surat al-Imran: 104). Demikian juga Allah Swt memerintahkan agar dakwah yang dilakukan mesti berdasarkan ilmu atau bashîrah (lihat surat Yusuf: 108).

Keberhasilan dakwah atau seruan sangat tergantung sejauh mana para juru dakwah memahami seluk-beluk yang berkaitan dengan dakwahnya. Para ulama juga menyebutkan ada beberapa unsur pokok dalam melaksanakan tugas dakwah, antara lain; Juru dakwah, objek dakwah, materi dakwah dan uslub dakwah atau metode dakwah.

\section{HASIL DAN DISKUSI}

\section{Dilandasi Ilmu dan Kelembutan}

Unsur-unsur pokok dakwah yang disebutkan di atas itu merupakan sesuatu yang amat penting dalam menunjang keberhasilan dakwah yang disampaikan. Terkadang dakwah yang tidak berhasil itu, salah satu sebabnya adalah kurangnya juru dakwah memperhatikan unsur-unsur dan pokok dakwah itu, Juru dakwah, objek dakwah, materi dakwah dan uslub dakwah atau metode dakwah.

Syaikh Shalih bin Fauzan al-Fauzan ${ }^{17}$, menyebutkan bahwa diantara pilarpilar dakwah Islam yang benar adalah yang pertama ilmu. Dengan dasar Ilmu inilah menurut beliau orang jahil tidak layak menjadi seorang da'i. Beliau berhujah diantaranya dengan surat Yusuf ayat $108 .{ }^{18}$

${ }^{16}$ KH. M. Isa Anshary, Mujahid Da'wah, Bandung: 1964, CV. Dipenogoro, hal 13.

${ }^{17}$ Anggota Komite Tetap untuk Riset Ilmiah dan Fatwa Kerajaan Saudi.

18 Lihat Prof. Rabi bin Hadi al-Madhali, Fiqih Dakwah Para Nabi, Bogor: Media Tarbiyah, 2006, lihat kata pengantar hal 2. 
Setiap da'i dalam menyampaikan dakwahnya, mengajak kepada kebaikan, menyuruh kepada kebenaran dan melarang dari kemungkaran (Ali Imran: 104), semuanya itu harus disampaikan dengan jalan baik, lembut dan bijaksana serta tidak meninggalkan persoalan baru. ${ }^{19}$ Atau dengan bahasa lain tidak mendatangkan kemungkaran yang lebih besar ${ }^{20}$. Sebagaimana Allah Jalla Wa'ala berfirman:

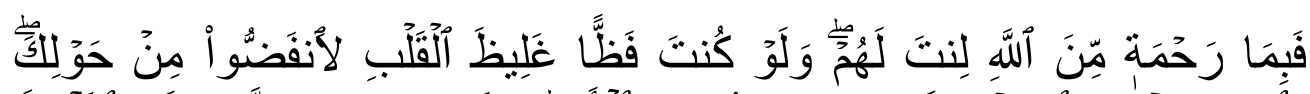

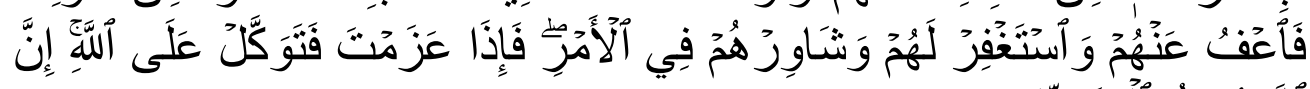

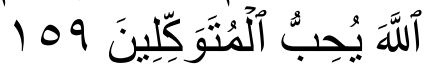

"Maka disebabkan rahmat dari Allah-lah kamu Berlaku lemah lembut terhadap mereka. Sekiranya kamu bersikap keras lagi berhati kasar, tentulah mereka menjaubkan diri dari sekelilingmu. karena itu ma'afkanlah mereka, mohonkanlah ampun bagi mereka, dan bermusyawaratlah dengan mereka dalam urusan itu. kemudian apabila kamu telah membulatkan tekad, Maka bertawakkallah kepada Allah. Sesunggubnya Allah menyukai orang-orang yang bertawakeal kepada-Nya". (QS. Ali Imran : 159).

Al-Qur'an dan as-Sunnah adalah petunjuk hidup setiap muslim. Keduanya menjadi pedoman dalam kehidupan setiap mukmin. Pedoman dalam kehidupan bermasyarakat, bergaul dengan manusia, bersikap dan bertindak sesuai dengan tuntunan keduanya, al-Qur'an dan as-Sunnah.

Ayat di atas sebagai satu pelajaran bahwa kelembutan sikap dalam melakukan dakwah adalah sebuah keharusan. Ketika dakwah yang dibangun tidak di atas landasan ilmu dan kelembutan, maka seringkali dakwah tidak mencapai hasil maksimal. Banyak ayat dan hadits yang menyuruh setiap muslim untuk senantiasa berlaku seperti itu, agar mengikuti contoh yang telah diajarkan oleh Nabi Muhammad Saw.

Ayat di atas sebagai gambaran bahwa al-Qur'an menyuruh kita untuk senantiasa berlemah lembut dalam mengajak dan menyeru ke jalan Allah dan Rasul-Nya.

Dalam menafsirkan ayat di atas, imam Ibnu Katsir dalam kitab tafsirnya ${ }^{21}$, menyebutkan bahwa firman Allah itu ditujukan kepada Rasulallah Saw. dan 1981, hal 8-9.

${ }^{19}$ Lihat KH. A. Syamsuri Siddiq, Da'wah \& Teknik Berhutbah, Bandung: PT. Alma'arif,

${ }^{20}$ Lihat lebih lanjut Yazid Abdul Qadir Jawas, Amar Ma'ruf Nahi Mungkar Menurut Ahlus Sunnah Wal Jama'ah, Bogor: Pustaka At-Taqwa, 2009.

${ }^{21}$ Lihat al-hafied Ibnu Katsier, Tafsir Ibnu Katsier juz I, hal 557. 
mengingatkannya atas karunia Allah yang telah diberikan kepadanya dan juga kepada orang-orang yang beriman, untuk menjadikan hati beliau Saw. lembut kepada umatnya.

Imam Ibnu Katsir melanjutkan, bahwa Nabi selalu bertutur kata lembut, sikap yang lemah lembut terhadap manusia. Tidak berhati kasar, berkata kasar, mengeluarkan kata-kata buruk. Kata al-Hasan al-Bashri yang demikian itu merupakan akhlak Nabi Muhammad Saw. yang dengannya Allah mengutusnya. ${ }^{22}$

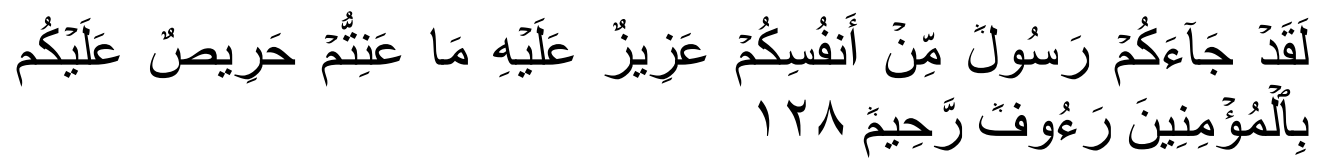

"Sungguh telah datang kepadamu seorang Rasul dari kaummu sendiri, berat terasa olehnya penderitaanmu, sangat menginginkan (keimanan dan keselamatan) bagimu, Amat belas kasiban lagi Penyayang terhadap orang-orang mukmin”. (QS. At-Taubah : 128).

Kata Abdullah bin Amer, Allah Swt. menjadikan Nabi saw seperti itu supaya manusia tertarik untuk memeluk Islam. Dan Abdullah bin Amer pun berkata, aku melihat sifat rasulallah saw. tidak bertutur kata kasar, tidak juga berhati kasar, tidak suka berteriak-teriak di pasar, tidak pernah membalas kejahatan dengan kejahatan. Tetapi beliau itu senantiasa memberikan maaf.

\section{Bersikap Lembut dan Bijaksana}

Contoh di atas adalah salah satu sikap kelembutan dan rabimnya Nabi Saw dalam berdakwah kepada umatnya. Dan mudahnya Nabi saw memaafkan orang yang berlaku buruk dan jahat terhadapnya. Itulah yang menjadi gambaran untuk kita bahwa bila mengajak dan berdakwah kepada manusia hendaknya dengan menggunakan kelemah-lembutan dan bijaksana.

Karena bila kita belaku kasar dan berhati kasar maka manusia akan jauh dari seruan dan ajakan kita. Padahal Islam mengajarkan untuk berlaku baik dan 'rabim' rasa sayang terhadap manusia.

Kelemah-lembutan adalah salah satu bentuk keberhasilan dakwah yang disampaikan kepada umat. Tidak sedikit manusia yang tertarik kepada Islam salah satunya disebabkan oleh kelemah-lembutan dakwah yang disampaikan. Tidak sedikit manusia yang lari dari dakwah kita disebabkan kita berlaku kasar dan berhati keras terhadap mereka.

22 Ibid, al-hafied Ibnu Katsier, Tafsir Ibnu Katsier juz I, hal 557. 
Dan para ulama memberikan nasehat agar mengajak manusia kepada agama yang agung ini dengan bijaksana dan perkataan yang santun serta dengan cara yang baik.

Sebagaimana Allah Swt. befirman:

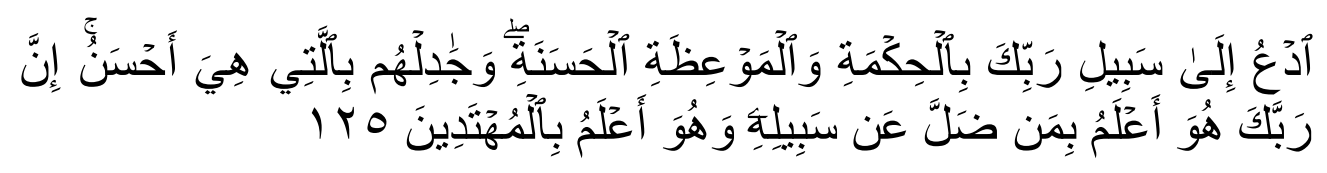

"Serulah (manusia) kepada jalan Tuban-mu dengan bikmah dan pelajaran yang baik dan bantablah mereka dengan cara yang baik. Sesunggubnya Tuhanmu Dialah yang lebih mengetabui tentang siapa yang tersesat dari jalan-Nya dan Dialah yang lebib mengetabui orang-orang yang mendapat petunjuk.". (QS. an-Nahl: 125)

Dengan kelemah-lembutan maka tabiat manusia akan menerima dan mengerti bahaya kemungkaran dapat mengetahui kesalahannya. Dan kembali menerima ajakan kebaikan tersebut dengan izin Allah Swt. dan bersegera ia bertaubat kepada Allah.

Ayat dan hadits ini menunjukan bahwa Islam tidak mengajarkan bentukbentuk radikalisme atau ekstrimisme. Bahkan, dalam ibadah sekalipun sikap ini adalah terlarang. Sebagaimana dalam sebuah hadits shahih Nabi Saw. pernah bersabda:

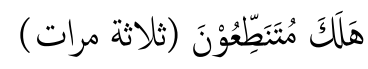

"Celaka dan binasa orang yang belampui batas dalam ibadab'. Hal itu diulang oleh nabi sebanyak tiga kali". 23

Sikap ghuluw atau ekstrim dalam ibadah saja dilarang, apa lagi diluar dari itu. Tentu lebih dilarang lagi. Apalagi seperti menghilangkan nyawa orang lain atau merusak harta benda orang lain yang bukan haknya, sekalipun harta itu milik orang yang berlainan agama dengan kita, itu jelas dilarang dalam agama kita.

Jika pengrusakan itu lebih besar dari itu, atau penghilangan nyawa yang lebih banyak lagi. Seperti melakukan tindakan terorisme atau yang semisalnya, maka cara-cara itu sama sekali tidak dibenarkan. Atau melakukan tindakan seperti peledakan bom, misalnya. Atau melakukan bom bunuh diri, dan dirinya terbunuh karena itu. Maka ulama ablussunnah menegaskan bahwa hal itu adalah terlarang

${ }^{23}$ Shahih Muslim, no 2055 dari sahabat Abdullah bin Mas'ud. 
dan haram hukumnya. Bukan hanya itu, pelakunya pun mendapatkan dosa besar. ${ }^{24}$ Sebagaimana hadits-hadits Nabi menjelaskan tentang perkara itu. ${ }^{25}$

Para ulama ablussunnab memberikan tentang hal itu, jangankan di negeri aman, (seperti di negeri kita ini) di daerah peperangan pun terlarang dan haram hukumnya. Inilah yang dinasehatkan oleh para ulama, syaikh Salim bin Ied alHilaly, syaikh Ali Hasan al-Halaby, dan ulama-ulama ablussunnab lainnya.

Oleh karenanya, sudah sangat jelas bahwa perbuatan itu tidaklah diajarkan oleh Allah Swt. dan Rasul-Nya, serta tidak diajarkan oleh para sahabat-sahabat Rasulallah saw. dan ulama-ulama ablussunnab yang datang sesudahnya.

Secara jelas al-Qur'an menerangkan tentang larangan itu. Allah swt dengan tegas melarangnya, sebagaimana termaktub dalam al-Qur'an al-Kariem. Allah Swt. berfirman:

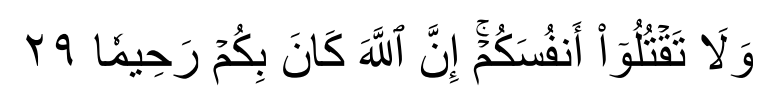

"Dan janganlab kamu membunub dirimu. Sesunggubnya Allab Maha Penyayang kepadamu”. (QS. An-Nisa: 29)

Bahkan, Imam Bukhari menyebutkan sebuah hadits dalam kitab shahihnya, bahwa Nabi saw. bersabda:

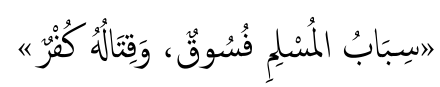

"Mencaci maki seorang muslim itu fasik dan membunubnya adalah sebuah kekufuran".

Dalam sebuah hadits shahih yang lain Nabi Muhammad Saw. bersabda:

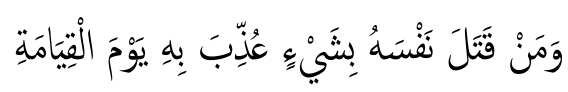

"Make a barang siapa yang membunub dengan sesuatu, maka ia akean disiksa dengannya pada hari kiamat kelak". (HR. Muslim).

\section{KESIMPULAN}

Para ulama diantaranya Syaikh Salim bin Ied al-Hilali, berpesan dan menasehati kita dalam melakukan dakwah di tengah-tengah umat harus dengan

${ }^{24}$ Lihat Fatwa-fatwa terlengkap Seputar Terorisme, Jihad dan Mengkafirkan Muslim, Abul Asybal bin Salim al-Mishri, Jakarta, Darul Haq, 2006, hal 583 dan halaman seterusnya.

${ }^{25}$ Sebagaimana disebut dalam sebuah lafadz hadits riwayat shahih Muslim. Bahkan al-Qur'an dengan tegas menyebutkan pelarangannya sebagaimana termaktub dalam an-Nissa: 29). 
al-Ilmu wa bilm, disertai dengan ilmu dan kelembutan. Dengan menggunakan ilmu yang benar sesuai contoh dan kaidah ulama dan disertai dengan kelemahlembutan. Dan Allah Ta’la pun menyebutkan dalam salah satu ayatnya dalam al-Qur'an. Allah befirman:

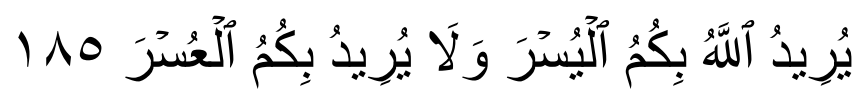

Allah menghendaki kemudahan bagimu, dan tidak menghendaki kesukaran bagimu. (al-Baqara: 185).

Dalam sebuah haditsnya Rasulallah Saw. bersabda:

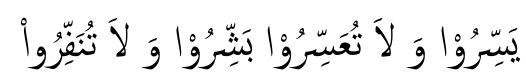

"Mudabkanlah dan jangan kalian mempersulit, gembirakanlab oleb kalian dan jangan menakut-nakuti".

Karena manusia sekarang ini umumnya hidup dalam kebodohan, ketidaktahuan (dalam urusan agama), kelalaian dan lebih mengutamakan dunia. Maka harus sabar dan penuh dengan hikmah sehingga dakwah ini terus berlanjut, dan sampai kepada manusia, sehingga mereka mau belajar Islam yang benar. Itu salah satu nasehat yang disampaikan diantaranya oleh Syaikh Abdullah bin Baz, ${ }^{26}$ dan ulama-ulama ahlus sunnah lainnya.

Mudah-mudahan risalah kecil ini bermanfaat untuk bahan kajian dan renungan dalam dakwah Islam untuk hari ini dan masa yang akan datang. Semoga. Allabu a'lam bishshawwab. Haq), hal 52.

${ }^{26}$ Lihat Fawwaz bin Hulayyin as-Suhaimi, Begini seharusnya berdakwah, (Jakarta: 2008, Darul 